The Sustainable City XIII 679

\title{
CONSTRUCTION WASTE MANAGEMENT IN UAE: AN EXPLORATORY STUDY
}

\author{
BATOUL Y. HITTINI \& AMNA I. SHIBEIKA \\ Architectural Engineering Department, UAE University, UAE
}

\begin{abstract}
In 2016, 9.68 million tons of solid waste were generated in Abu Dhabi alone where $67.8 \%$ was sent to dumpsites and landfills. In the same year, the construction and demolishing (C\&D) industry produced $47 \%$ of the non-hazardous waste. This research aims to investigate the C\&D waste management in UAE's construction industry, specifically in Abu Dhabi based on (a) official resources identifying authorized entities, regulations, implementation guidelines, and causes behind waste generation in UAE' C\&D industry; and (b) unstructured interviews with construction professionals in Abu Dhabi revealing the waste management consideration process, enhancement methods, professionals' responsibilities and views toward the topic. While Abu Dhabi's sustainability framework (Estidama) requires a submittal of C\&D Waste Management Plan (CDWMP) prior to any construction activity asking for a minimum of $30 \%$ waste diversion from landfills, relevant literature highlighted awareness as an effective factor in $C \& D$ management. Interviews for this study have shown that a lack of awareness is still affecting the C\&D waste management and control negatively. Interviewees have also contributed in understanding the waste management consideration process, enhancement methods, professionals' responsibilities and views toward the topic highlighting that implementation practices seem to seek Estidama certification but not a sustainable environment.
\end{abstract}

Keywords: waste management, construction, regulations, practices, implementation, UAE, Abu Dhabi.

\section{INTRODUCTION}

Sustainable development is one of the most important aims of today's society where waste represent one of the hurdles that need to be overcome. The landfills dumped waste consists of organic and non-organic materials; the first tends to generate harmful emissions overtime adding to the greenhouse gases (GHG) harming the environment by contributing to climate change. Such dumped materials anaerobic decomposition produces Methane gas $\left(\mathrm{CH}_{4}\right)$ that is 21 times stronger than Carbon dioxide $\left(\mathrm{CO}_{2}\right)$ as a greenhouse gas, other than the severe odour and potential explosion hazards in addition to the GHG produced during transportation from the waste source to the disposal site. Moreover, it affects biodiversity subjecting animals to risk especially for those live near to dumpsites/landfill, contaminates the soil, limits land use of surrounding areas and pollute groundwater [1].

Environment Agency of Abu Dhabi (EAD) has reported that $6.9 \%$ of the total GHG was emitted by the waste sector; $92 \%$ of which was emitted by solid waste disposal in Abu Dhabi's landfills [2]. In 2016, about 4.55 million tonnes of waste was generated by C\&D industry representing $47 \%$ of total non-hazardous waste produced [3] increased by $62.92 \%$ compared to 2015 when $34 \%$ of the total non-hazardous waste was generated by C\&D practices transferring $66 \%$ of the total to landfill, dumpsites or others [1]. It worth mentioning that in $2014 \mathrm{Abu}$ Dhabi had only one small sanitary landfill, 10 legal dumpsites, 4 recycling facilities, 2 incineration plants and 4 composting facilities, compared to around 23,000 illegal dump sites leading to only $1.51 \%$ solid waste sanitary landfill disposal [4]. The generated waste by C\&D industry in UAE typically includes mixed solid and food waste, metal/scrap steel, paper/cardboard, pallets, masonry, Roofing (asphalt), plastics, wood, roads asphalt, ceiling tiles cuttings, concrete and glass, and gypsum/drywall [5]. Moreover, the population 
is expected to be doubled by 2040 which means an increase of housing demand and double of waste production [6].

This research aims to explore the $C \& D$ waste management in construction industry in UAE, specifically in Abu Dhabi based on official resources and unstructured interviews. This paper is organized as follows; Section 2 presents literature review which highlights C\&D rules and regulations of Abu Dhabi and causes behind waste in UAE, and Section 3 outlines the research methodology, results and discussion representing waste management consideration process, CDWMP common enhancement techniques and professionals' views toward waste management in Abu Dhabi are presented in Section 4 and finally Section 5 concludes the paper and highlights future research.

\section{LITRATURE REVIEW}

C\&D waste legislation differs across the emirates of UAE. For example, all the new constructions after 1 March 2014 in Dubai had to implement the Green Building Regulations and Specifications (GBRS) [7] requiring 50\% diversion of construction generated waste [8]. Ras Al Khaimah (RAK) emirate sat the target of construction waste management in Burjeel regulations in December 2018 to be the reduction of waste sent to landfills decreasing the demand on raw materials. It also requires labelled waste skips and segregation. Date stamped photos and invoices of RAK waste management agency represent the appropriate evidence for the authority [9].

\subsection{Waste management in Abu Dhabi}

Waste in Abu Dhabi Emirate is being considered under the provision of EAD that was established in 1996 seeking air quality, groundwater and the biodiversity protection and enhancement in Abu Dhabi Emirate desert and marine ecosystems looking forward to raising the environmental awareness, facilitating sustainable development and ensuring environmental sustainability to remain as one of the top priorities of the UAE agenda [3]. EAD has assigned waste management responsibilities to be split among three main institutions; Tadweer for municipal solid, commercial, medical, agricultural, industrial, construction and demolition waste, ADNOC for oil and gas waste and FANR for radioactive waste [1]. Centre of Waste Management Abu Dhabi (CWM) and the Department of Municipal Affairs (DMA) represent other supportive authorities for waste reduction in Abu Dhabi [10].

In 2014, EAD has published Abu Dhabi Environment Policy Agenda (ADEPA) to be followed focusing on six main guiding principles (a) avoiding waste generation and reduce it as much as possible; (b) maximizing reusing; (c) proceeding with recycling for certain precious materials; (d) recovering high value materials that cannot be recycled to be a source of energy; (e) improving treatment of waste that cannot be utilized; and (f) providing controlled sanitary engineered landfills targeting a diversion of $85 \%$ of the generated waste from landfills [13] in 2021 [14]. ADEPA aims to improve waste regulations, ensure effective enforcement, enhance the quality of waste data, and promote awareness and education in terms of waste management across key sectors between 2016 and 2020 [15]. In November 2015, Tadweer established Abu Dhabi Waste Management Master Plan 2040 (ADWMMP2040) [14] while the detailed goals are not available for public. In April 2016, the first committee meeting regarding ADWMMP-2040 was held aiming to clarify the waste situational analysis and characteristics [16] followed by a second meeting in December 2016 representing a workshop for stakeholders [17]. 


\subsection{C\&D waste management rules and regulations of Abu Dhabi}

The Urban Planning Council (UPC) released Estidama Pearl Rating System in 2009 addressing sustainability of structures. All of new private buildings from February 2011 and after, are mandated to achieve 1 pearl while all of new governmental buildings has to achieve two pearls [11]. The Pearl Building Rating System (PBRS) Stewarding Materials section sets three requirements related to (a) Hazardous materials elimination; (b) basic construction waste management; and (c) basic operational waste management, and twelve other optional credits.

The required section entitled "basic construction waste management" is the only mandated requirement related to construction waste asking for CDWMP to be submitted before any construction/demolition activity specifying the materials that are planned to be diverted from landfills, the segregation location (onsite/offsite) and the use of the planned salvage materials targeting $30 \%$ of construction generated waste to be recycled/salvaged excluding the hazardous waste [12] in addition to a signed contract with a waste management services firm that will transfers recyclable waste to its final destination where the firm is required to submit monthly following up report as well as trips sheets copies stamped from the final destination. Moreover, Estidama requires colour coded waste skips and three different languages signage considering the workers different cultures. It also requires a Pearl Qualified Professional (PQP) certified from Estidama to facilitate a workshop to the contractor and the safety site engineers defining Estidama requirements in terms of waste control, material submittals and procurement. The project's PQP has to visit the site weekly for waste following up and monitoring as he is required to update the waste calculator monthly according to the manifests created by centre of waste management in Abu Dhabi filled by the contractor clarifying the quantity of waste shifted from the site (by weight or volume), its final destination (to be recycled or landfills) and the hauler company information [10].

EAD has suggested implementation actions to enhance the success of CDMWP including (a) employees engagement by informing them about the top management goals and objectives beside to their support, (b) on-site waste segregation, (c) auditing and monitoring waste keeping the records and the details of amounts and final destinations of waste generated, (d) specify the waste licensed transporter, (e) promote training and awareness for workers on-site, and (f) continuously review and update the CDWMP [5].

\subsection{Causes behind waste generation in UAE}

Lack of awareness was highlighted as one of the main direct causes behind waste generation in UAE construction industry [18] challenging Estidama implementation [10]. In 2015, a survey was conducted with construction industry professionals shedding lights on lack of awareness and education; $96.5 \%$ of the survey's participants agreed that lack of awareness significantly impact the waste generation as well as different cultures and mentalities supported by 92 , but $68 \%$ of them didn't attend any programme that supports waste reduction or control [10]. Construction waste generation could be referred to other reasons such as excessive off-cuts resulting from poor design, lack of government legislation and policies, lack on contractual incentives, lack of local recycling facilities and lack of company's supportive managers [18], weak waste collection, weak waste transportation, improper waste recycling behaviours, governmental role towards construction waste reduction, material procurement handling, and lack of implementing site waste management plan [10]. 


\section{METHODOLOGY}

A qualitative approach was selected since it's the most appropriate to explore the views and experiences giving the opportunity for better understanding [19] of waste management in construction sites. Specifically, unstructured interviews that are defined as interviews that neither have a fixed questions nor answers [20] while it's addressed as appropriate method of understanding complex people behaviour regardless of categories for best exploration which is the aim for this research [21].

Exploratory unstructured interviews were conducted with seven professionals between March and May 2019 aiming to understand waste management practices in Abu Dhabi's construction sites. The interviewees are currently involved in Estidama projects representing client, consultant, supervision, and commissioning agents in Abu Dhabi. Simple thematic analysis that is defined as "a process of encoding qualitative information" representing "a bridge between qualitative and quantitative research" [22] was used to analyse the interviews of this study.

\section{RESULTS AND DISCUSSION}

The participants of this study included Senior Sustainability Site Manager, MEP Manager, Sustainable Project Manager, Senior Project Manager, Lead Sustainability Engineer, Vice President Design and Development Manager, and Architectural Designer. Six of them have accomplished PQP certification. The interviewees have clarified the process of considering waste management in Abu Dhabi construction sites, the involved professionals in such process, CDWMP common enhancement techniques, and their views toward the topic.

\subsection{Waste management consideration process and involved professionals}

The common process to consider waste management in Abu Dhabi construction sites starts from CDWMP submittal by the project's consultants identifying (a) the targeted percentage of waste to be diverted from landfills; (b) the segregation type to be at source or collected in certain areas. Although, research has indicated that segregation at source requires less efforts and time, and results in better segregation quality compared to central designated areas and off-site segregation [23] but the common practice in Abu Dhabi is to sort waste after collection in certain areas specified by the project's consultant as well. Segregation at source is selected only when the space is not enough for central waste collection areas; and (c) the pathway of waste hauler in the construction site where a certified hauler only can transfer waste from the construction site to its last distention considering amounts' documentation by weight or volume to update the project's waste status using online e-manifest (Bolisaty) managed by and reporting to Tadweer highlighting that all of the records has to be stamped from the waste end distention whether it's a landfill or recycling facility. Referring to the quotes below, it's common to accomplish high waste diversion percentages in the firstsecond quarters of the project.

"If we don't get 60-70\% of waste diversion in the first-second quarters, then we're in a trouble".

Senior Sustainability Site Manager

"Construction materials are more common to be recycled than finishing materials”. 
Estidama team review and approve the appropriate CDWMP's. Then, they coordinate five audits to construction sites ensuring compliance. During the first, they ensure that the locations of waste collection areas, bins and labels are satisfying the approved CDWMP. Afterwards, they only confirm that waste documentation was done properly referring to the quote of Lead Sustainability Engineer: "Estidama team usually will not say about housekeeping or other things, they ensure that the documentation was properly done". On the next professional hierarchical level; the PQP certified from Estidama has to arrange for regular monthly visit to ensure the compliance with Estidama, confirm and sign the recorded waste amount and take pictures for documentation. In case of incompliance or improper activity, PQP has the right to report to the project manager directly.

\subsection{Professionals' views toward construction waste management practices in Abu Dhabi}

The data shows that the human factor is key for construction waste management as suggested by one of the interviewees;

"Waste compliance is one of the major challenges in site operations because it depends on the labours".

\section{Lead Sustainability Engineer}

Another interviewee goes further to highlight the challenge of changing labours over the course of the project or from project to project

"With training the culture of the worker will grow, and experience will grow but remember we are in a place where worker may work for five years in the project then go back to their own country, new people are coming so training is always required but the culture doesn't develop because people are going and to coming back".

\section{President Design and Development Manager}

This quote above, shows that training and labours' experience gained over time are useful to improve $\mathrm{C} \& \mathrm{D}$ waste management practices, however, this need to be regularly updated as workers tend to join and leave projects at different times.

Four out of seven interviewees agreed that raising awareness will affect the amount of waste generated while the rest thinks that it only informs the labour about dealing with waste after its generation; as where to dispose it and not to through food beverages as example but it doesn't affect the generation rate as MEP Manager had stated:

"The common training doesn't reduce waste, which is produced on-site, it's more about segregation, if you want amount control then you need another training to reduce the source, usually it's only about segregation".

Then the common trainings then are conducted to accomplish the requirements but not looking for waste reduction although it's the first guiding principle in EAD's waste management policy as mentioned earlier [13]. If current trainings/instructions are changed to inductions clarifying the impact of waste and sustainability on employee's/labour's personal life, family, and even country, such an induction may encourage them for much better performance. Therefore, awareness is still affecting the $\mathrm{C} \& \mathrm{D}$ waste management and control negatively, not only on labours level but even on professionals'. 
Designers and architectural consultants don't consider waste reduction as well referring to the quote below although standardization and modular coordination are expected to reduce waste effectively from early project's stages as highlighted by literature [24].

"The waste requirements as one of the easiest since our responsibility is limited to identification of the targeted percentage of waste to diverted from landfills, segregation type and pathways of waste hauler in construction site”.

Architectural Designer

Consultants' practices seek Estidama certification instead of a sustainable environment. They spend efforts only on activities that are counted for Estidama credits referring as in procurement and specifications to the quotes below.

"Designers don't usually consume effort or time unless such a method is accounted for Estidama credits that could be gained by consider recyclable products during procurement instead".

Architectural Designer

“Consultants are responsible about providing specification”.

President Design and Development Manager

Reduction of waste starts from creating a suitable CDWMP, or as a Senior Project Manager asserts: "Good plan will reduce" each project is unique, therefore CDWMP need to be based on analyzing the project's strengths and weaknesses instead of submitting a typical plan for different projects. Two outstanding CDWMP implementation case studies are addressed by literature support the interviewees opinion where the first succeeded to divert $96 \%$ of waste from landfills [25] and the second reduced the waste sent to landfills by $43 \% 50 \%$ of the waste handling fees through establishing the cost difference between recycling and landfills dumping activities [26].

\subsection{CDWMP common enhancement methods}

Although interviewed professionals have considered the seven implementation actions suggested by EAD to enhance the success of CDWMP EAD as mentioned earlier in the literature, but they have spent more efforts toward considering the human factor in the process [5] where it's common to share the Estidama targets with the Health, Safety and Environment (HSE) department that enhance the labours awareness toward sustainability and waste management practices through (a) photo labels added to bins considering the labours' educational level, (b) direct instructions/inductions from their foremen and supervisors clarifying segregation type and waste collection areas, and (c) rewards and incorporeal incentives as organizing trips and deigning one day off for the best performers in terms of waste management. In critical projects, punishment system could be used to ensure the compliance to the CDWMP through salary deduction or transferring the culpable worker to another project.

\section{CONCLUSION AND FUTURE RESEACH}

This study aimed to explore the C\&D industry in terms of waste management in UAE, specifically in Abu Dhabi through (a) official resources identifying authorized entities, regulations, implementation guidelines, and causes behind waste generation in UAE' C\&D industry; and (b) unstructured interviews with construction professionals in Abu Dhabi 
revealing the waste management consideration process, enhancement methods, professionals' responsibilities and views toward the topic. The study highlighted that the regulations relative to $C \& D$ waste management were mandated by Estidama requiring CDWMP submittal and a minimum of $30 \%$ diversion of generated waste prior to any construction activity. Literature has addressed lack of awareness as an important factor that is affecting C\&D waste generation negatively in consistency with this study. The interviewees of this study have also clarified the process of waste management consideration as well as the involved professionals in such process in addition to their views toward the topic. Participants of this research have revealed that implementation practices in Abu Dhabi are seeking Estidama certification but not the sustainability environment. As a result, waste reduction is not considered by designers and architectural consultants for example. Future research may test the effectiveness of current human factor enhancement methods in terms of waste management in Abu Dhabi; in case of negative indication then a study could be conducted to analyse the current methods and propose better approaches referring to international successful CDWMP. Another study could focus on certain profession cultural analysis and find out the critical physiological factors that may encourage them for better sustainable performance.

\section{ACKNOWLEDGEMENT}

I would like to express my deepest gratitude to all the interviewees who provided their precious time for voluntary participation in this research.

\section{REFERENCES}

[1] EAD, Abu Dhabi State of Environment Report 2017, 2017.

[2] EAD, Greenhouse Gas Inventory for Abu Dhabi Emirate. www.ead.ae/wp-content/ uploads/2014/03/AD-Greenhouse-gas-inventory-Eng.pdf.

[3] EAD, Annual Report 2017, 2017.

[4] Environment Agency - Abu Dhabi, Waste and environment 2016, 2016.

[5] EAD, Sustainable Construction and Demolition Waste Management in Abu Dhabi.

[6] Geranpayeh, S., Abu Dhabi's waste to double in the next 25 years. Gulf News. https://gulfnews.com/news/uae/environment/abu-dhabi-s-waste-to-double-in-thenext-25-years-1.1622404. Accessed 20 Feb. 2019.

[7] Dubai Municipality, Government of Dubai, Circular No. (198) 2014, 2014.

[8] Dubai Municipality, Government of Dubai, Dubai Electriciy and Water Authority, Green Building Regulations and Specifications, 2011.

[9] Municipality Department, Government of Ras Al Khaimah, Barjeel, Ras Al Khaimah Green Building Regulations, 2018.

[10] Yahya, M.M., Sustainable solutions for construction waste reduction, The British University in Dubai, 2015.

https://bspace.buid.ac.ae/bitstream/1234/947/1/120177.pdf.

[11] Estidama, Estidama Pearl Rating System: Information Bulletin \#3, 2011.

[12] UPC, Estidama. The Pearl Rating System for Estidama, building rating system design and construction, 2010.

[13] EAD, Waste management, Waste as a source of energy, 2014.

[14] US Green Building Council, Emirates Green Building Council, World Green Building Council. Green Building City Market Brief, 2017.

[15] EAD, Strategic Plan 2016-2020. 
[16] Waste and Recycling Middle East, Abu Dhabi Waste Master Plan 2040 holds first Steering Committee Meeting, 2016. www.waste-recyclingme.ae/abu-dhabi-wastemaster-plan-2040-holds-first-steering-committee-meeting/. Accessed 22 Jun. 2019.

[17] Bhatia, N., Tadweer meets for Abu Dhabi Waste Master Plan 2040. Construction Week, 2019. www.constructionweekonline.com/article-42280-tadweer-meets-forabu-dhabi-waste-master-plan-2040. Accessed 22 Jun. 2019.

[18] Al-Hajj, A. \& Hamani, K., Material waste in the UAE construction industry: Main causes and minimization practices. Archit. Eng. Des. Manag., 7, pp. 221-235, 2011.

[19] Gill, P., Stewart, K., Treasure, E. \& Chadwick, B., Methods of data collection in qualitative research : Interviews and focus groups, pp. 291-295.

[20] Minichiello, V., Aroni, R., Timewell, E. \& Alexander, L., In-depth Interviewing: Researching People, Taylor and Francis Books Ltd, 1992.

Punch, K.F., Introduction to Social Research: Quantitative and Qualitative Approaches, 3rd ed., SAGE, 1998. https://books.google.ae/books?hl=en\&lr=\&id=G2 fOAgAAQBAJ\&oi=fnd\&pg=PP1\&dq=Introduction+to+Social+Research:+Quantitat ive + and + Qualitative + Approaches\&ots $=\mathrm{j} 3 \mathrm{sEzkaJAu \& sig=H0zbFAhD0G5u6ZrYM9}$ B-6q9BE_Y\&redir_esc=y\#v=onepage \&q=IntroductiontoSocialResearch\%3AQua.

[21] Boyatzis, R.E., Transforming Qualitative Information: Thematic Analysis and Code Development, SAGE, 1998.

[22] Poon, C.S., Yu, A.T.W. \& Ng, L.H., On-site sorting of construction and demolition waste in Hong Kong. Resour. Conserv. Recycl., 32, pp. 157-172, 2001.

[23] Ajayi, S.O. \& Oyedele, L.O., Critical design factors for minimising waste in construction projects: A structural equation modelling approach. Resour. Conserv. Recycl., 137, pp. 302-313, 2018.

[24] Zero Waste Scotland, Case study: Strathclyde Fire and Rescue Training Centre, 2015. www.wrap.org.uk/sites/files/wrap/Strathclyde case study final web.pdf.

[25] Mcdonald, B. \& Smithers, M., Implementing a waste management plan during the construction phase of a project: A case study. Constr. Manag. Econ., 16, pp. 71-78, 1998. 